\title{
Ionic liquids as Efficient Catalysts for The Glycolysis of Polyethylene Terephthalate
}

\author{
A.M. Al-Sabagh, F.Z. Yehia*, A.M.F. Eissa**, M.E. Moustafa**, \\ Gh. Eshaq ${ }^{*}$, A.M. Rabie ${ }^{*}$ and A.E. El Metwally ${ }^{* \#}$ \\ Department of Petroleum Applications, Department of \\ Petrochemicals, Egyptian Petroleum Research Institute, Nasr \\ City, Cairo 11727 and ${ }^{* *}$ Department of Chemistry, Faculty of \\ Science, Benha University, Egypt.
}

\begin{abstract}
7 HE GLYCOLYSIS of polyethylene terephthalate (PET) was studied using several ionic liquids as catalysts. The Lewis base ionic liquid, 1-butyl-3-methylimidazolium acetate [Bmim][OAc], exhibits higher catalytic activity for the glycolysis of PET, compared with 1-butyl-3 methylimidazolium chloride $([\mathrm{Bmim}] \mathrm{Cl})$ and 1-butyl3 -methylimidazolium bromide $([\mathrm{Bmim}] \mathrm{Br})$. The results revealed that the [Bmim][OAc] has a PET conversion of $75.1 \%$ and bis (2hydroxyethyl) terephthalate (BHET) yield of $46.4 \%$ under the conditions of $1.0 \mathrm{~g}$ of [Bmim] [OAc] with $20 \mathrm{~g}$ of ethylene glycol in the presence of $2.0 \mathrm{~g}$ of PET at $180^{\circ} \mathrm{C}$ after $2 \mathrm{hr}$ of glycolysis. The main glycolysis product (BHET) was analyzed using XRD, NMR, EIMS, FTIR, TGA and DSC.
\end{abstract}

Keywords: Catalysis, Ionic liquid, Glycolysis, Polyethylene terephthalate and Recycling .

Increased environmental awareness, legislative measures and public demand for environmental sustainability are leading to an increased interest in plastics recycling. The amount of plastic production has been increasing significantly each year, with uses including fiber, packing, containers and building materials, among others ${ }^{(1,2)}$. Poly (ethylene terephthalate) (PET) is a semi-crystalline thermoplastic polyester with high chemical and impact resistance at room temperature. PET is extensively used in diverse applications, such as textiles, high-strength fibers, photographic films and disposable soft-drink bottles, due to its excellent mechanical properties, chemical stability, safety, light weight, transparency and air-tightness ${ }^{(3,4)}$, which has resulted in a continuously growing stream of PET material ${ }^{(5)}$. The total global PET consumption has risen to 54 million metric tons in 2010 and is expected to grow by $4.5 \%$ per year from 2010 to $2015^{(6)}$. Thus, the effective recycling of PET waste has been regarded as one of the most important ways of resolving "white pollution", saving resources and protecting the environment ${ }^{(7,8)}$. Therefore, an ecologically safe method of recycling plastics, such as PET, remains an important scientific and societal goal.

At present, the conventional methods of PET recycling are mainly divided into physical methods and chemical methods. The physical methods of recycling 
produce some plastic products with inferior properties. However, the chemical methods can recycle PET waste to produce monomers that can be used as raw materials to produce virgin plastic products ${ }^{(9)}$. Considering the quality of the recycled products, chemical methods are particularly attractive and have been studied widely. These methods mainly include methanolysis, hydrolysis and glycolysis, which have been developed on commercial or pilot scales ${ }^{(10,11)}$. Glycolysis is the most promising approach due to its advantages of low-volatility solvents and continuous production feasibility. The main product of the glycolysis of PET is the virgin monomer (BHET), which can be used to make PET production units, textile softeners and unsaturated polyester resins ${ }^{(12)}$.

The glycolysis reaction is very slow in the absence of catalyst ${ }^{(13,14)}$ and is an extremely sluggish process. In recent years, many catalysts have been developed for the glycolysis of PET, such as metal acetates $(\mathrm{Zn}, \mathrm{Co}, \mathrm{Pb} \text { and } \mathrm{Mn})^{(8,15,16)}$, titanium phosphate, solid superacids, metal oxides, carbonates ${ }^{(17)}$ and sulfates ${ }^{(18)}$. However, these catalysts have several drawbacks, such as the need for high temperatures and high pressures, difficult separation of the catalyst from the depolymerized products, the occurrence of side reactions and the impurity of the products $^{(19,20)}$. Therefore, it is necessary to develop a new catalyst for the glycolysis of PET.

Recently, ionic liquids (ILs) ${ }^{(21-24)}$ have been used as environmentally friendly catalysts in the degradation of PET under mild conditions ${ }^{(25)}$ because of their adjustable physical and chemical properties, attracting the attention of scholars from various fields, such as synthesis, catalysis, separation and electrochemistry ${ }^{(26)}$. The special properties of ionic liquids make it easier to separate the catalyst from the solid glycolysis products. Wang et al. ${ }^{(12)}$ used an ionic liquid as a catalyst for the glycolysis of PET; however, the conversion of PET and selectivity toward BHET were very low, and the process was very slow. They also studied the glycolysis of PET using a Fe-containing magnetic ionic liquid, which exhibited higher catalytic activity than conventional ILs. However, the monomer produced is very easily stained by the Fe-containing ILs $^{(27)}$.

The aim of this investigation was to apply the acetate-based ionic liquid [Bmim][OAc] as a catalyst in the glycolysis of PET to avoid the negative environment and health effects of chlorine-containing IL catalysts.

To the best of our knowledge, the use of [Bmim][OAc] as a catalyst for the glycolysis of PET has yet to be published.

\section{Materials}

\section{Experimental}

PET pellets $(3.2 \times 2.8 \times 4 \mathrm{~mm})$ were purchased from Hangzhou Zhenghan Biological Technology Co., Ltd. The intrinsic viscosity of PET was measured in a 60:40 (w/w) phenol/1,1,2,2-tetra-chloroethane solution at $25^{\circ} \mathrm{C}$ and found to be $0.64 \mathrm{dLg}^{-1}$. Using the Mark-Houwink method, the weight average molecular weight $\left(4.1 \times 10^{4} \mathrm{gmol}^{-1}\right)$ was calculated from this intrinsic viscosity. Analytical-

Egypt. J. Chem. 57, No. 4 (2014) 
grade ethylene glycol (EG), 1-butyl-3-methylimidazolium chloride ([Bmim] $[\mathrm{Cl}]$ ), 1-butyl-3-methylimidazolium bromide ([Bmim $][\mathrm{Br}])$ and ethanol were obtained from Sigma-Aldrich. 1,1,2,2-Tetrachloroethane, potassium acetate and phenol were obtained from Merck.

Synthesis of 1-butyl-3-methylimidazolium acetate ([Bmim][OAc])

1-Butyl-3-methylimidazolium acetate ([Bmim][OAc]) was synthesized according to the procedures described in the literature ${ }^{(28)}$.

General procedure for the glycolysis of PET

A 50-ml round-bottom three-necked flask equipped with a thermometer and a reflux condenser was loaded with $2.0 \mathrm{~g}$ of PET, $20.0 \mathrm{~g}$ of ethylene glycol and a certain amount of catalyst. The glycolysis reactions were carried out under atmospheric pressure at reaction temperatures ranging from $150^{\circ} \mathrm{C}$ to $190^{\circ} \mathrm{C}$ for glycolysis times of 1-4 hr. The flask was immersed in an oil bath at a specific temperature for the required time. When the glycolysis reaction was complete, the undepolymerized PET pellets were quickly separated from the liquid phase before the products precipitated. An excess amount of cold distilled water was used to wash the undepolymerized PET pellets, and the water was then mixed with the product fraction. The undepolymerized PET was collected, dried and weighed. The conversion of PET is defined by Eq. (1):

$$
\text { Conversion of PET }(\%)=\frac{\mathrm{W}_{0}-\mathrm{W}_{1}}{\mathrm{~W}_{0}} \times 100 \%
$$

where $\mathrm{W}_{0}$ represents the initial weight of PET and $\mathrm{W}_{1}$ represents the weight of undepolymerized PET. Meanwhile, the glycolysis product mixture was vigorously agitated (cold distilled water would dissolve the remaining ethylene glycol, catalyst and monomer) and then filtered. The collected filtrate was concentrated to approximately $150 \mathrm{ml}$ by a vacuum rotary evaporator at $50^{\circ} \mathrm{C}$. The concentrated filtrate was stored in a refrigerator at $0^{\circ} \mathrm{C}$ for $24 \mathrm{hr}$. White crystalline flakes were formed in the filtrate and then separated and dried. This material was the bis(hydroxyethyl) terephthalate (BHET) monomer. The fraction insoluble in cold water was a mixture of the dimer and oligomers. The products were analyzed using XRD, NMR, EI-MS, FTIR, TGA and DSC. The selectivity of the BHET monomer is defined by Eq. (2), while the yield is defined by Eq. (3):

$\begin{array}{llll}\text { Selectivity of BHET }(\%) & =\frac{\mathrm{W}_{\mathrm{BHET}} / \mathrm{MW}_{\mathrm{BHET}}}{\mathrm{W}_{\mathrm{PET}, \mathrm{D}} / \mathrm{MW}_{\mathrm{PET}}} \times 100 \% & \text { Eq. (2) } \\ \text { Yield of BHET }(\%) & =\frac{\mathrm{W}_{\mathrm{BHET}} / \mathrm{MW}_{\mathrm{BHET}}}{\mathrm{W}_{\mathrm{PET}, \mathrm{I}} / \mathrm{MW}_{\mathrm{PET}}} \times 100 \% & \text { Eq. (3) }\end{array}$


where $\mathrm{W}_{\mathrm{PET}, \mathrm{D}}, \mathrm{W}_{\mathrm{PET}, \mathrm{I}}$ and $\mathrm{W}_{\mathrm{BHET}}$ refer to the weight of depolymerized PET, the initial weight of PET and the weight of BHET, respectively. $\mathrm{MW}_{\text {BHET }}$ and $\mathrm{MW}_{\mathrm{PET}}$ are the molecular weights of BHET $\left(254 \mathrm{gmol}^{-1}\right)$ and the PET (192 $\mathrm{gmol}^{-1}$ ) repeating unit, respectively.

\section{Characterization}

The main product was analyzed by $\mathrm{H}^{1}$ NMR using an ECA $500 \mathrm{MHz}$ instrument (JEOL, Japan) in DMSO-d6 solution. Fourier transform infrared spectroscopy (FTIR) measurements were performed using a Nicolet IS-10 FTIR instrument with $\mathrm{KBr}$ discs. The mass spectrum of the main product was obtained on an ISQ single-quadrupole MS (Thermo Scientific) instrument with electron ionization (EI). X-ray diffraction (XRD) patterns of the main product and PET material were recorded in the range $2 \theta=4-80^{\circ}$ using a Philips powder diffractometer with $\mathrm{Cu} \mathrm{K \alpha}$ radiation $(\mathrm{k}=0.154 \mathrm{~nm})$. The instrument was operated at $40 \mathrm{kV}$ and $40 \mathrm{~mA}$. The spectra were recorded at a scanning rate of $2^{\circ}$ $\theta /$ min. Thermogravimetric analysis (TGA) and differential scanning calorimetry (DSC) of the main product and PET were performed using a SDTQ 600 system (USA) by heating from room temperature to $1000^{\circ} \mathrm{C}$ at a rate of $10^{\circ} \mathrm{C} / \mathrm{min}$ in a nitrogen atmosphere.

\section{Results and Discussion}

\section{Characterization of the synthesized ionic liquid}

Figure. 1 shows the FTIR spectrum of the synthesized ILs. The spectrum of [Bmim][OAc] (Fig. 1) shows that the major peaks in the IR spectra are assigned to acetate $\mathrm{C}=\mathrm{O}$ bond stretching $\left(1570-1579 \mathrm{~cm}^{-1}\right), \mathrm{C}-\mathrm{O}$ stretching $\left(1379-1403 \mathrm{~cm}^{-1}\right)$, C-H stretching (2963-2966 $\left.\mathrm{cm}^{-1}\right), \mathrm{C}-\mathrm{C}$ stretching $\left(918 \mathrm{~cm}^{-1}\right), \mathrm{O}-\mathrm{C}-\mathrm{O}$ bending $\left(650 \mathrm{~cm}^{-1}\right)$, imidazole $\mathrm{C}-\mathrm{N}$ stretching $\left(1337 \mathrm{~cm}^{-1}\right), \mathrm{C}-\mathrm{H}$ stretching $\left(3104 \mathrm{~cm}^{-1}\right)$, side chain $\mathrm{C}-\mathrm{H}$ stretching $\left(2874 \mathrm{~cm}^{-1}\right)$, and $\mathrm{C}-\mathrm{N}-\mathrm{C}$ bending $\left(623 \mathrm{~cm}^{-1}\right)$. The $\mathrm{C}-\mathrm{H}$ peaks between 3100 and $3200 \mathrm{~cm}^{-1}$ can be attributed to aromatic $\mathrm{C}-\mathrm{H}$ stretching, whereas those below $3000 \mathrm{~cm}^{-1}$ can be attributed to aliphatic $\mathrm{C}-\mathrm{H}$ stretching ${ }^{(29,30)}$. The observed aromatic $\mathrm{C}-\mathrm{H}$ stretching is characteristic of $\mathrm{C}-\mathrm{H}-----\mathrm{O}$ hydrogen bonds $^{(31)}$.

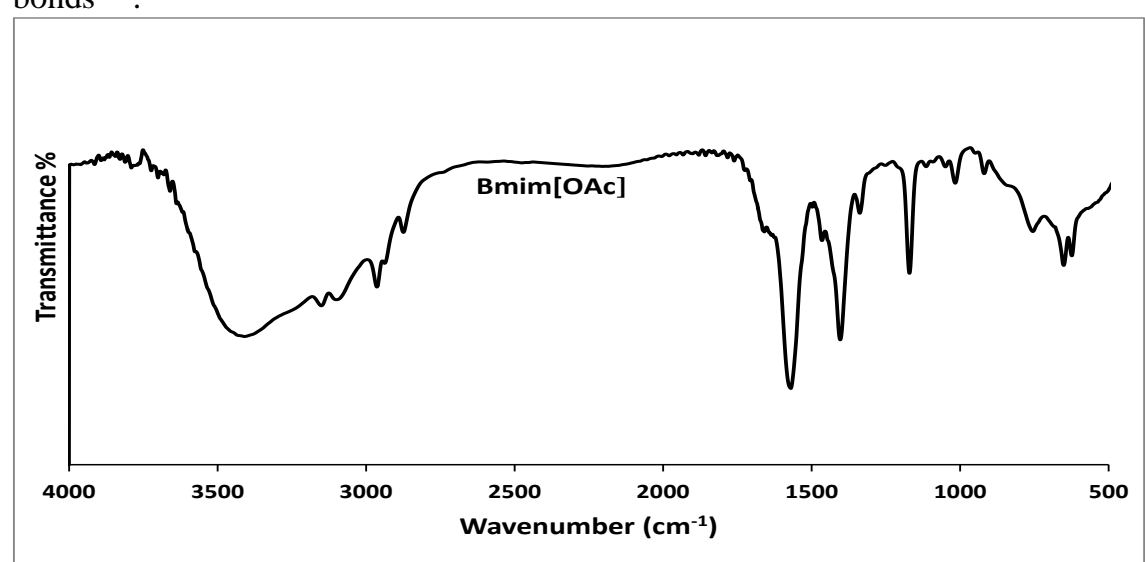

Fig. 1. FTIR spectra of [Bmim] [OAc $]$.

Egypt. J. Chem. 57, No. 4 (2014) 


\section{Qualitative analysis of the main degradation product}

To identify the structure of the main product in the degradation of PET in EG catalyzed by [Bmim][OAc], NMR, EI-MS, XRD, DSC, TGA and FTIR characterizations were performed. The main product was also identified by measuring the melting temperature, which is found to be $110.9^{\circ} \mathrm{C}$. The EI-MS spectrum in Fig. 2 shows that the molecular weight of the main product is 254 $\mathrm{g} / \mathrm{mol}$, which is the same as that of BHET.

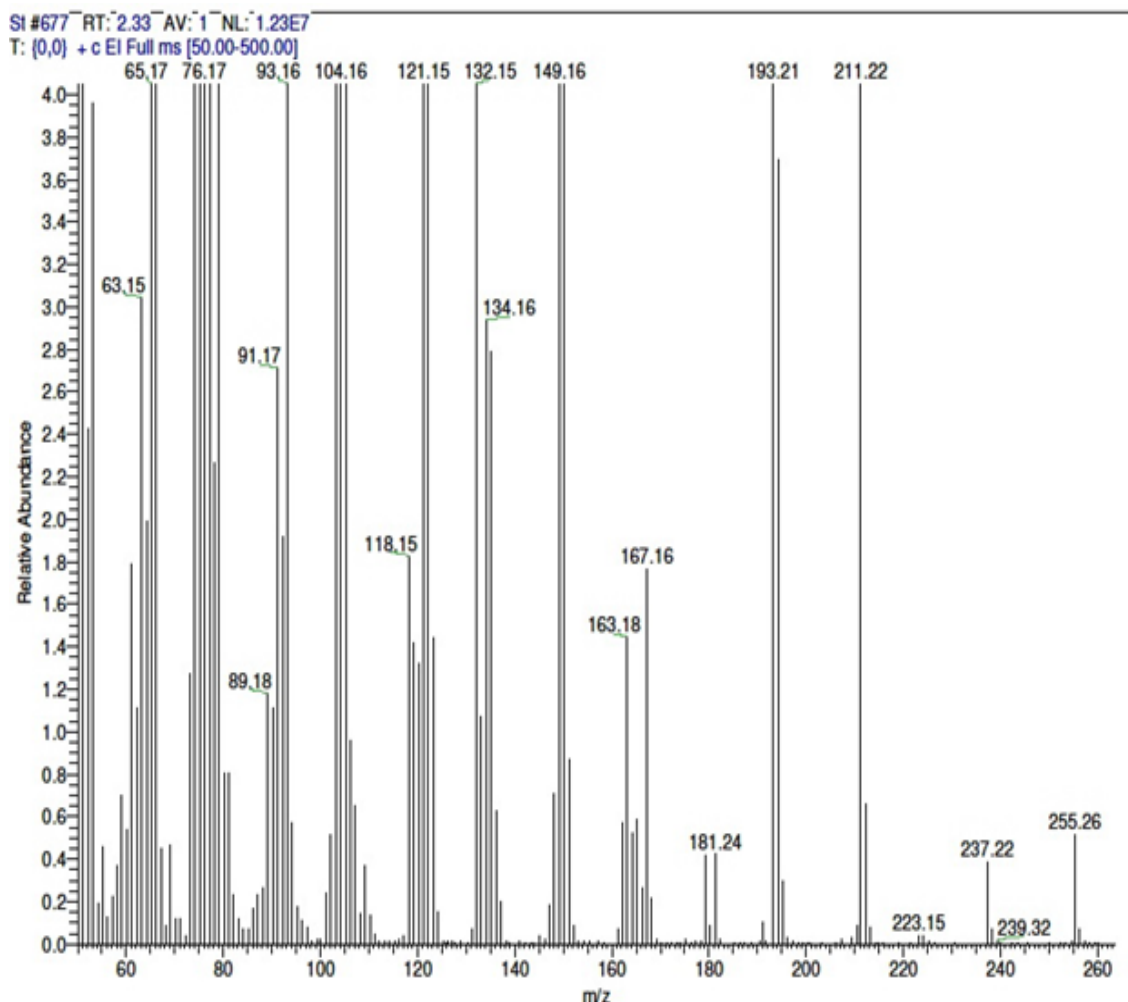

Fig. 2. EI-MS spectrum of BHET.

Figure 3 compares the XRD patterns of BHET and the PET material. PET exhibits a typical diffraction pattern due to the crystalline structure of this polyester, with broader diffraction peaks at $2 \theta=16.4^{\circ}, 17.7^{\circ}$ and $23.0^{\circ}$. The diffraction peaks of BHET are narrower and more intense than those of PET, which illustrates that the BHET obtained by this method has a high crystallinity and a different crystalline structure than PET. 


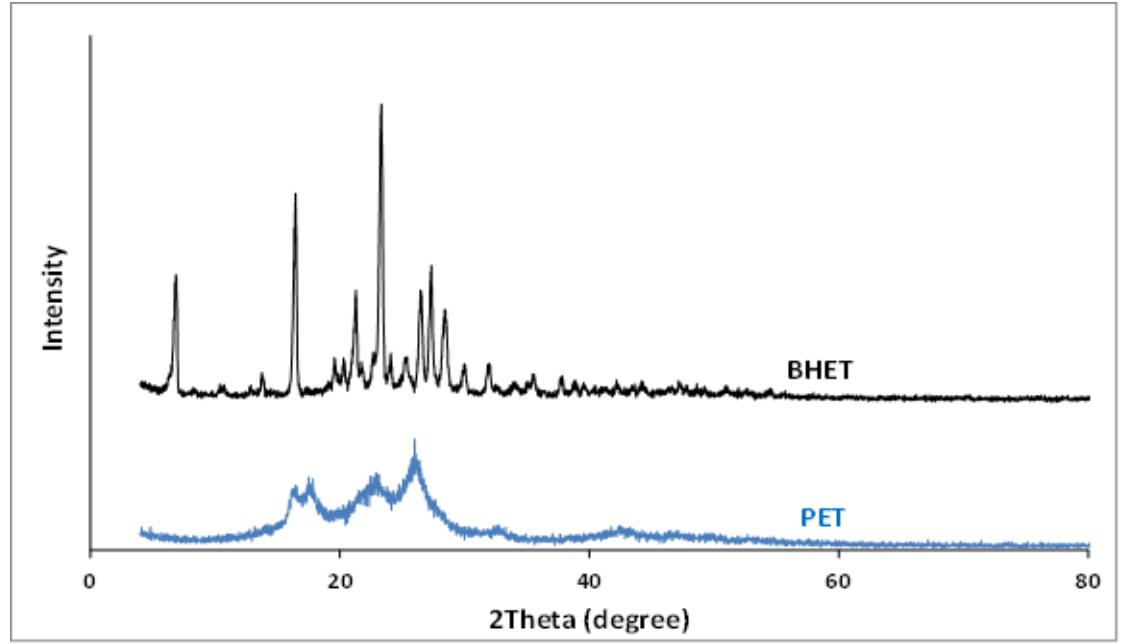

Fig. 3. XRD spectra of BHET and PET.

The DSC curve in Fig. 4 shows a sharp endothermic peak at $110^{\circ} \mathrm{C}$. The melting onset temperature and peak temperature of BHET are 110.9 and $110^{\circ} \mathrm{C}$, respectively.

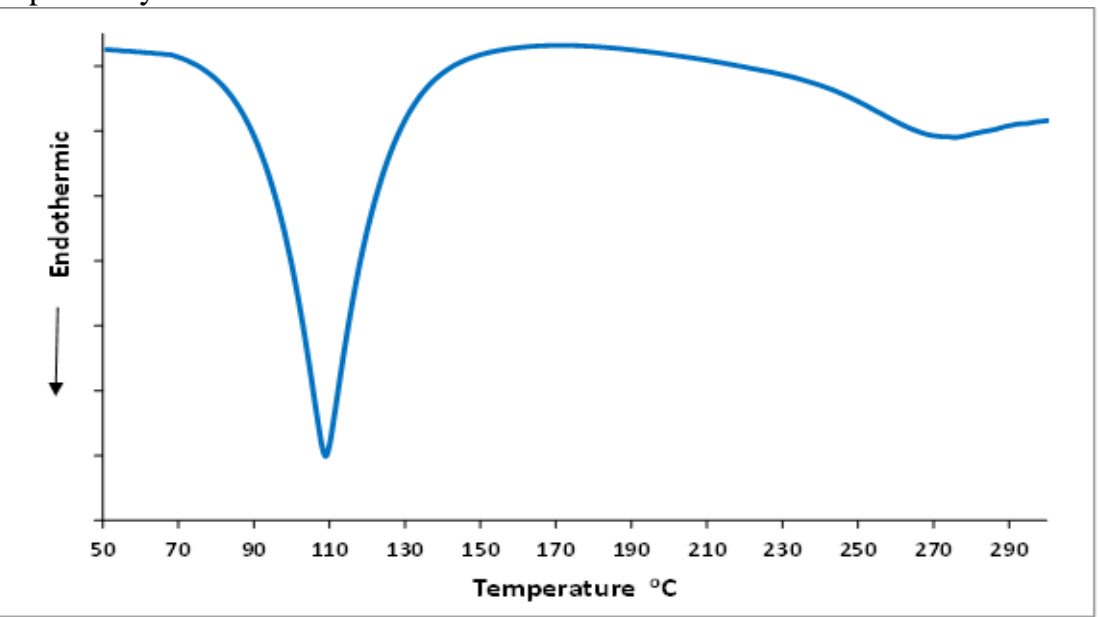

Fig. 4. DSC curve of BHET

The TGA curves of the PET material and BHET are illustrated in Fig. 5. The TGA curve of PET shows significant weight loss at $400^{\circ} \mathrm{C}$, which is attributed to the thermal decomposition of PET $^{(32,25)}$. The TGA curve of BHET exhibits two clear weight losses. The first is approximately $32 \%$ at an onset temperature of $240^{\circ} \mathrm{C}$ due to the thermal decomposition of BHET. During the heating process in TGA analysis, BHET repolymerizes to PET. The other loss is approximately $60 \%$ at an onset temperature $400^{\circ} \mathrm{C}$ due to the thermal decomposition of PET produced by the BHET thermal polymerization during TGA analysis ${ }^{(32)}$.

Egypt. J. Chem. 57, No. 4 (2014) 


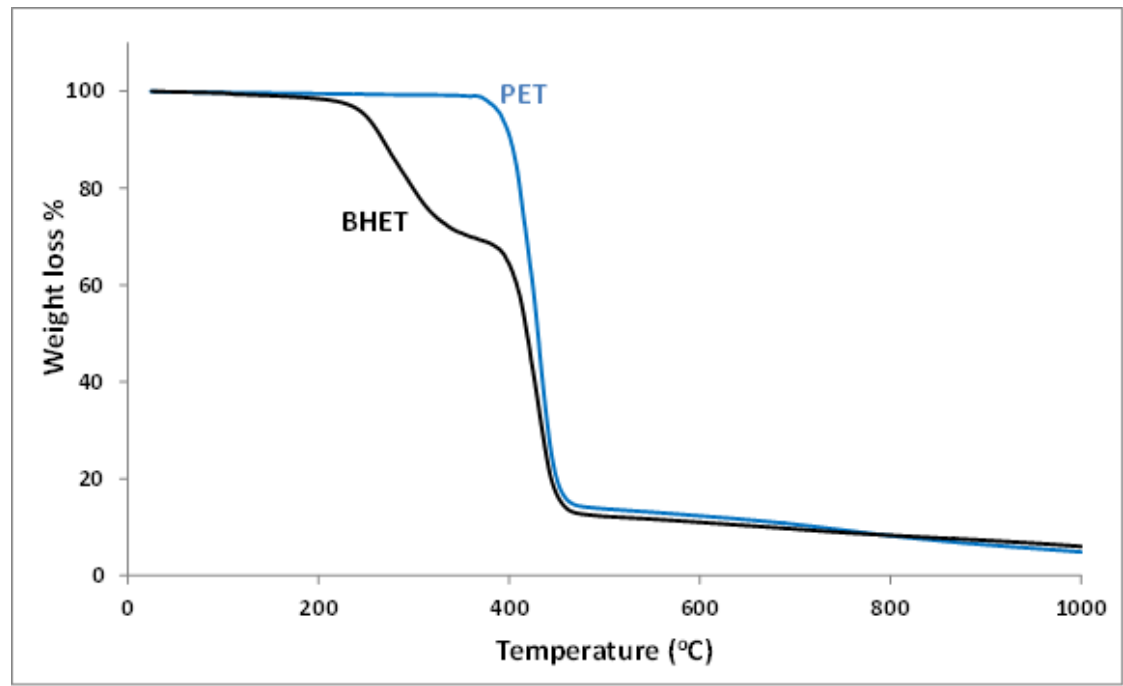

Fig. 5. TGA curves of BHET and PET.

Figure 6 shows the FTIR spectra of the BHET product and PET material. The FTIR spectra of the BHET monomer clearly showed an $\mathrm{OH}$ band at $3450 \mathrm{~cm}^{-1}$ and $1135 \mathrm{~cm}^{-1}, \mathrm{C}=\mathrm{O}$ stretching at $1715 \mathrm{~cm}^{-1}$, alkyl C-H at 2879 and $2954 \mathrm{~cm}^{-1}$ and aromatic C-H at $1411-1504 \mathrm{~cm}^{-1}$, which are all present in $\mathrm{BHET}^{(33,34)}$.

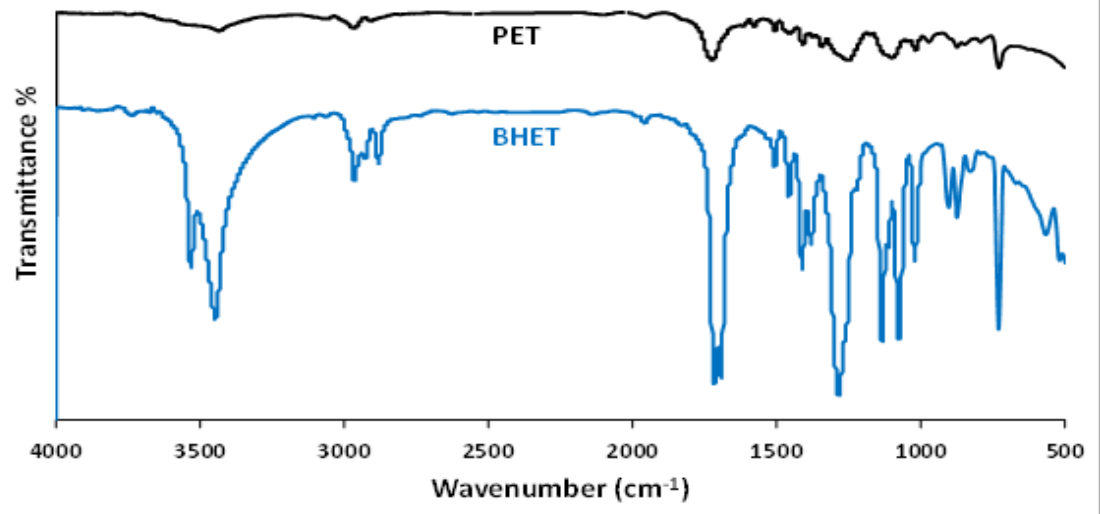

Fig. 6. FTIR spectra of BHET and PET.

The $\mathrm{H}^{1}$ NMR spectrum of BHET is presented in Fig. 7. The single signal at $\delta 8.1 \mathrm{ppm}$ indicates the presence of the four aromatic protons of the benzene ring. The triplet at $4.3 \mathrm{ppm}$ and the quartet at $3.7 \mathrm{ppm}$ represent the methylene protons of $\mathrm{COO}-\mathrm{CH}_{2}$ and $\mathrm{CH}_{2}-\mathrm{OH}$, respectively. The triplet at $\delta 4.9 \mathrm{ppm}$ is characteristic of the protons of the hydroxyl. The $\mathrm{H}^{1} \mathrm{NMR}$ spectrum also agrees very well with those reported in the literature ${ }^{(35-37)}$. 


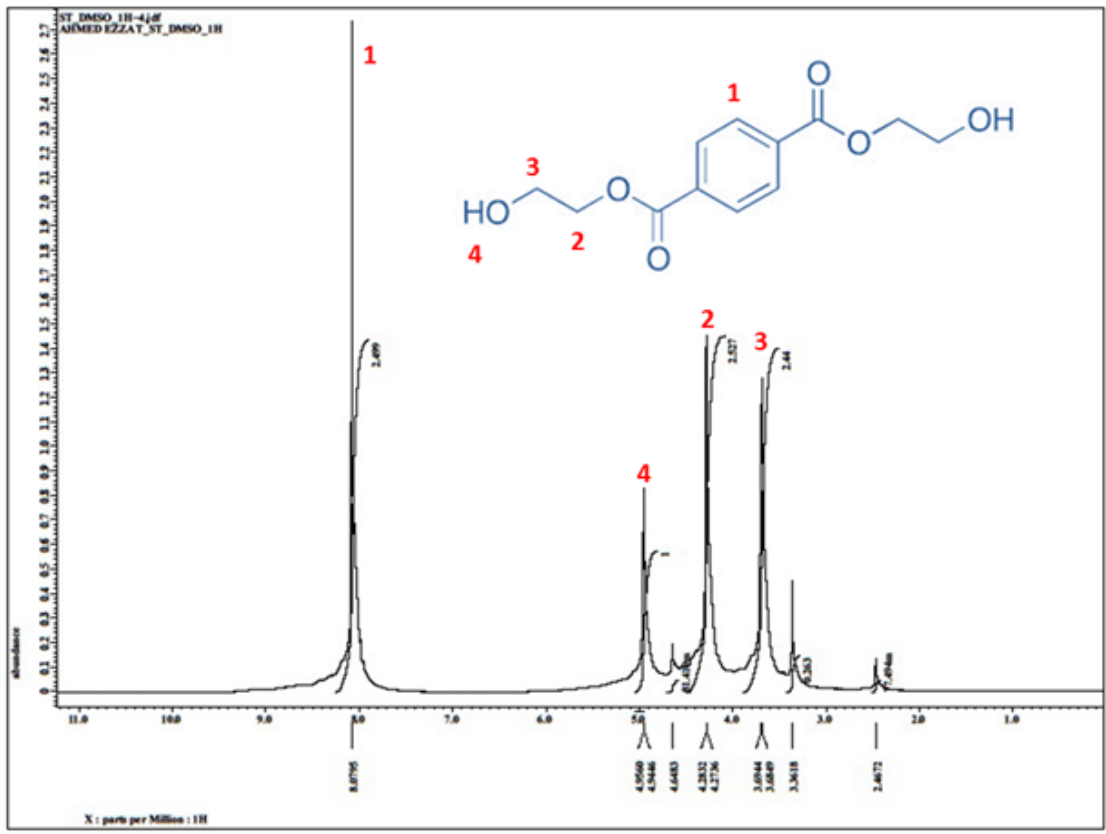

Fig. 7. H $^{1}$ NMR spectrum of BHET.

Effect of catalysts on the glycolysis of PET

The catalytic performance of various ionic liquid catalysts was examined in the glycolysis reaction of PET. As seen from Table 1, in the presence of the Lewis neutral ionic liquids $[\mathrm{Bmim}][\mathrm{Br}]$ and $[\mathrm{Bmim}][\mathrm{Cl}]$, no glycolysis of PET took place. However, when [Bmim] [OAc] was used as a Lewis base catalyst under the same conditions, the conversion of PET was $75.1 \%$, the selectivity of BHET was $61.9 \%$, and the yield was $46.4 \%$. This demonstrates that [Bmim][OAc] has an excellent catalytic activity for the glycolysis of PET, as the degradation reaction occurred under relatively mild conditions with a higher reaction extent.

TABLE 1. Catalytic effect of different ionic liquids on the glycolysis of PET. ${ }^{\text {a }}$

\begin{tabular}{cccc}
\hline Ionic liquids & $\begin{array}{c}\text { Conversion of PET } \\
(\boldsymbol{\%})\end{array}$ & $\begin{array}{c}\text { Selectivity of BHET } \\
(\boldsymbol{\%})\end{array}$ & $\begin{array}{c}\text { Yield of BHET } \\
(\boldsymbol{\%})\end{array}$ \\
\hline- & 0 & 0 & 0 \\
{$[\mathrm{Bmim}][\mathrm{Br}]$} & 0 & 0 & 0 \\
{$[\mathrm{Bmim}][\mathrm{Cl}]$} & 0 & 0 & 0 \\
{$[\mathrm{Bmim}][\mathrm{OAc}]$} & $75.1 \%$ & $61.9 \%$ & $46.4 \%$ \\
\hline
\end{tabular}

${ }^{\mathrm{a}}$ Reaction conditions: PET (2.0 g), EG (20 g), ionic liquid $(1.0 \mathrm{~g}), 1 \mathrm{~atm}, 180{ }^{\circ} \mathrm{C}, 2 \mathrm{hr}$.

Egypt. J. Chem. 57, No. 4 (2014) 


\section{Degradation mechanism for PET glycolysis}

There has been some debate on the mechanism of the degradation of PET. Researchers ${ }^{(27,39,40)}$ have reported that the degradation of PET resulted from the cleavage of the ester group in PET. In some studies, it has been found that the degradation of PET occurred in the amorphous phase and at the chain folds on the crystal surface ${ }^{(41,42)}$.

The mechanism and supposed pathway of the glycolysis of PET catalyzed by the Lewis base ionic liquid [Bmim] [OAc] ${ }^{(43,44)}$ are illustrated in Scheme 1; this process is a Lewis base catalytic reaction. When [Bmim][OAc] is added, it is assumed that there exists a synergic effect between the cation and anion of this catalyst $^{(45)}$. The cation of this ionic liquid, $[\mathrm{Bmim}]^{+}$, interacts with the carbonyl oxygen $(\mathrm{C}=\mathrm{O})$ in the ester of PET. The oxygen in the hydroxyl group of ethylene glycol then attacks the carbon cation of the ester group, forming a tetrahedral intermediate. Meanwhile, the anion of the catalyst [OAc] $]^{-}$interacts with the hydrogen in the hydroxyl group of ethylene glycol, resulting in the oxygen of ethylene glycol becoming more negative and better able to attack the carbon cation of the ester group, breaking the $\mathrm{C}-\mathrm{O}$ bond in PET. Lastly, the hydrogen in ethylene glycol leaves and combines with [OAc] ${ }^{-}$to form acetic acid as an intermediate. The acetic acid then partially dissociates to give $\mathrm{H}^{+}$and an acetate ion. In this case, the EG molecule and carbon are connected, a new ester group is formed, and the chain of PET is cleaved. The electrons on the oxygen in $-\mathrm{O}\left(\mathrm{Bmim}^{+}\right)$then transfer, forming $\mathrm{C}=\mathrm{O}$. The acyl-oxygen cleaves and the $-\mathrm{OCH}_{2} \mathrm{CH}_{2}-$ group leaves, combining with $\mathrm{H}^{+}$to form $\mathrm{HOCH}_{2} \mathrm{CH}_{2}-$.

The depolymerization of PET proceeded step-by-step, and oligomers, dimers and monomers were generated sequentially. With the progress of the reaction, an increasing number of BHET monomers emerged, which might polymerize into dimers or oligomers, creating a chemical equilibrium ${ }^{(27)}$.

\section{Conclusion}

In summary, it is demonstrated that [Bmim][OAc] could behave as an efficient and eco-friendly catalyst for the glycolysis of PET in ethylene glycol. Using [Bmim] [OAc] $(1.0 \mathrm{~g})$ with $20 \mathrm{~g}$ of EG and $2.0 \mathrm{~g}$ of PET, it is found that only $2 \mathrm{~h}$ of glycolysis at $180^{\circ} \mathrm{C}$ is sufficient for the conversion of PET to reach $75.1 \%$ and the yield of BHET to reach $46.4 \%$. The synergistic effect of the cation and anion in the Lewis base ionic liquid [Bmim][OAc] facilitates the attack of the oxygen in ethylene on the carbon cation of the ester group. The acetate-based ionic liquid $[\mathrm{Bmim}][\mathrm{OAc}]$ might have the potential to substitute traditional compounds to catalyze the glycolysis of PET in industrial production.

Acknowledgments: Financial support by the Egyptian Petroleum Research Institute is gratefully acknowledged. 

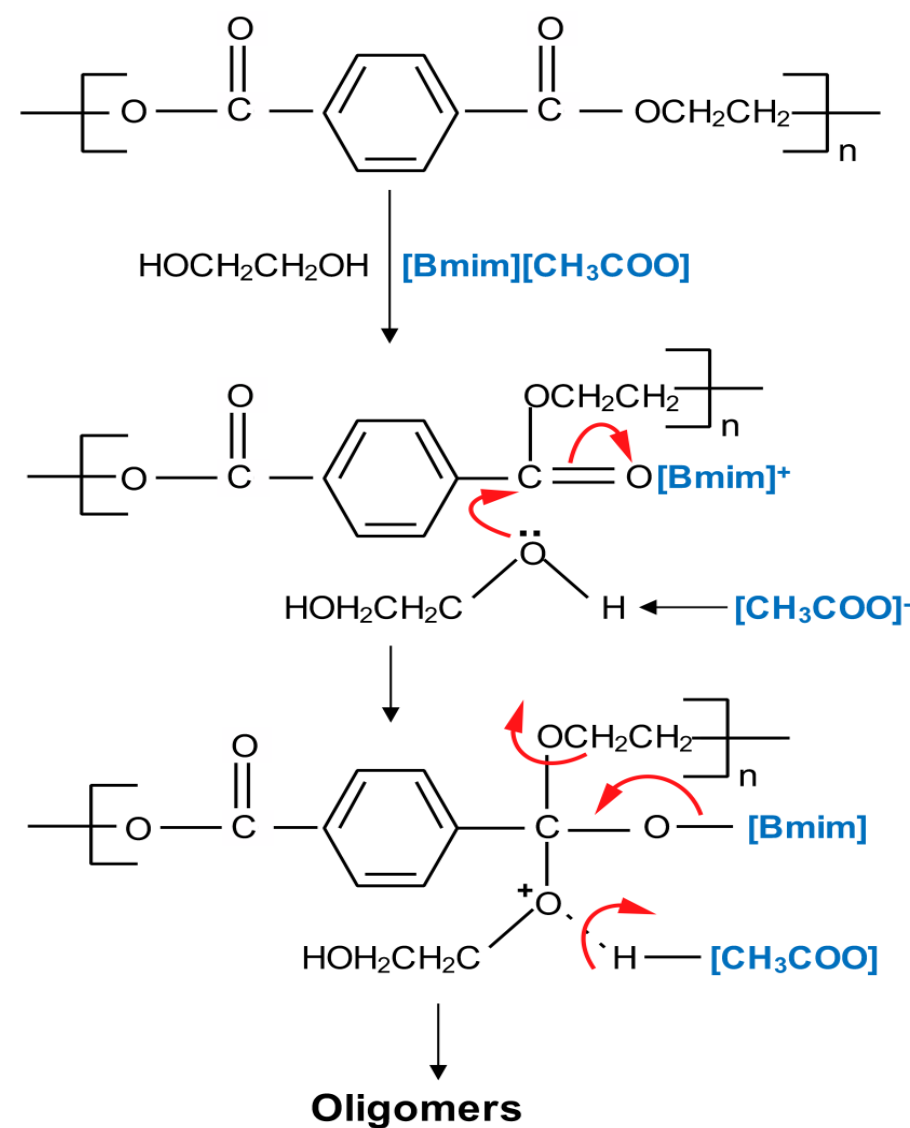<smiles>OCCCCCCCO</smiles><smiles>O=C(OCCO)c1ccc(C(=O)OCCO)cc1</smiles>

Scheme 1. Mechanism of the glycolysis of PET catalyzed by [Bmim][OAc]. 


\section{References}

1. Genta, M., Iwaya, T., Sasaki, M., Goto, M. and Hirose, T., Depolymerization mechanism of poly (ethylene terephthalate) in supercritical methanol. Ind. Eng. Chem. Res. 44, 3894-3900 (2005).

2. Al-Salem, S.M., Lettieri, P. and Baeyens, J., Recycling and recovery routes of plastic solid waste (PSW): a review. Waste Manage. 29, 2625-2643 (2009).

3. Fang, T.H., Wu, C.D. and Kang, S.H., Thermomechanical properties of polymer nanolithography using atomic force microscopy. Micron, 42, 492-497 (2011).

4. Huck, W.T.S., Materials chemistry: Polymer networks take a bow. Nature, 472, 425 426 (2011).

5. Colomines, G., Lee, A.V.D., Robin, J.J. and Boutevin, B., Study of the crystallinity of polyesters derived from the glycolysis of PET. Macromol. Chem. Phys. 207, 14611473 (2006).

6. Bartolome, L., Imran, M., Cho, B.G., Al-Masry, W.A. and Kim, D.H., Recent developments in the chemical recycling of PET, In: D. Achilias (Eds.), Material Recycling - Trends and Perspectives, ISBN: 978-953-51-0327-1, InTech, pp. 65-84 (2012).

7. Awaja, F. and Pavel, D., Recycling of PET. Eur. Polym. J. 41, 1453-1477 (2005).

8. Sánchez, A.C. and Collinson, S.R., The selective recycling of mixed plastic waste of polylactic acid and polyethylene terephthalate by control of process conditions. Eur. Polym. J. 47, 1970-1976 (2011).

9. Liu, F., Cui, X., Yu, S., Li, Z. and Ge, X., Hydrolysis reaction of poly (ethylene terephthalate) using ionic liquids as solvent and catalyst. J. Appl. Polym. Sci. 114, 3561-3565 (2009).

10. Grunschke, H., Hammerschick, W. and Naucheim, B., Process for depolymerizing polyethylene-terephthalate to terephthalic acid dimethyl ester. U.S. Patent 3403115 , (1968).

11. Datye, K.V. and Vaidya, A.A., Chemical Processing of Synthetic Fibers and Blends, John Wiley and Sons, New York (1984).

12. Wang, H., Liu, Y., Li, Z., Zhang, X., Zhang, S. and Zhang, Y., Glycolysis of poly (ethylene terephthalate) catalyzed by ionic liquids. Eur. Polym. J. 45, 1535-1544 (2009).

13. Troev, K., Grancharov, G., Tsevi, R., Gitsov, I., A novel catalyst for the glycolysis of poly (ethylene terephthalate). J. Appl. Polym. Sci. 90,1148-1152 (2003).

14. Pingale, N.D., Palekar, V.S. and Shukla, S.R., Glycolysis of postconsumer polyethylene terephthalate waste. J. Appl. Polym. Sci. 115, 249-254 (2010) . 
15. López-Fonseca, R., Duque-Ingunza, I., de Rivas, B., Arnaiz, S. and GutiérrezOrtiz, J.I., Chemical recycling of post-consumer PET wastes by glycolysis in the presence of metal salts. Polym. Degrad. Stabil. 95, 1022-1028 (2010).

16. Xi, G., Lu, M. and Sun, C., Study on depolymerization of waste polyethylene terephthalate into monomer of bis (2-hydroxyethyl terephthalate). Polym. Degrad. Stabil. 87,117-120 (2005).

17. Shukla, S.R. and Kulkarni, K.S., Depolymerization of poly (ethylene terephthalate) waste. J. Appl. Polym. Sci. 85,1765-1770 (2002).

18. Shukla, S.R. and Harad, A.M., Glycolysis of polyethylene terephthalate waste fibers. J. Appl. Polym. Sci. 97, 513-517 (2005).

19. Peters, T.A., Benes, N.E., Holmen, A. and Keurentjes, J.T., Comparison of commercial solid acid catalysts for the esterification of acetic acid with butanol. Appl. Catal. AGen. 297, 182-188 (2006).

20. Moreno, J.I., Jaimes, R., Gómez, R. and Niño -Gómez, M.E., Evaluation of sulfated tin oxides in the esterification reaction of free fatty acids. Catal. Today, 172, 34-40 (2011).

21. Lee, H.N. and Lodge, T.P., Poly (n-butyl methacrylate) in ionic liquids with tunable lower critical solution temperatures (LCST). J. Phys. Chem. B 115,1971-1977 (2011).

22. Bhargava, B.L., Yasaka, Y. and Klein, M.L., Computational studies of room temperature ionic liquid-water mixtures. Chem. Commun. 47, 6228-6241(2011).

23. Cooper, E.R., Andrews, C.D., Wheatley, P.S., Webb, P.B., Wormald, P. and Morris, R.E., Ionic liquids and eutectic mixtures as solvent and template in synthesis of zeolite analogues. Nature, 430,1012-1016 (2004).

24. Cui, G., Wang, C., Zheng, J., Guo, Y., Luo, X. and Li, H., Highly efficient $\mathrm{SO}_{2}$ capture by dual functionalized ionic liquids through a combination of chemical and physical absorption. Chem. Commun. 48, 2633-2635 (2012).

25. Wang, H., Li, Z., Liu, Y., Zhang, X. and Zhang, S., Degradation of poly(ethylene terephthalate) using ionic liquids. Green Chem. 11,1568-1575 (2009).

26. Pârvulescu, V.I. and Hardacre, C., Catalysis in ionic liquids. Chem. Rev. 107, 26152665 (2007).

27. Wang, H., Yan, R., Li, Z., Zhang, X. and Zhang, S., Fe-containing magnetic ionic liquid as an effective catalyst for the glycolysis of poly (ethylene terephthalate). Catal. Commun. 11,763-767 (2010) .

28. Liu, F., Li, L., Yu, S., Lv, Z. and Ge, X., Methanolysis of polycarbonate catalysed by ionic liquid [Bmim][Ac]. J. Hazard. Mater. 189, 249-254 (2010).

29. Tait, S. and Osteryoung, R.A., Infrared study of ambient-temperature chloroaluminates as a function of melt acidity. Inorg. Chem. 23, 4352-4360 (1984).

Egypt. J. Chem. 57, No. 4 (2014) 
30. Dieter, K.M., Dymek, C.J., Heimer, N.E., Rovang, J.W. and Wilkes, J.S., Ionic structure and interactions in 1-methyl-3-ethylimidazolium chloride-aluminum chloride molten salts. J. Am. Chem. Soc. 110, 2722-2726 (1988).

31. Elaiwi, A., Hitchoock, P.B., Seddon, K.R., Srinivasan, N., Tan, Y.M., Welton, T. and Zora, J.A., Hydrogen bonding in imidazolium salts and its implications for ambient-temperature halogenoaluminate (III) ionic liquids. J. Chem. Soc. Dalton Trans. 21, 3467-3472 (1995) .

32. Chen, C.H., Study of glycolysis of poly (ethylene terephthalate) recycled from postconsumer soft - drink bottles. III. Further investigation. J. Appl. Polym. 87, 2004-2010 (2003) .

33. Ikladious, N.E., Recycling of poly(terephthalate): identification of glycolysis products. J. Elastom. Plast. 32, 140-151 (2000).

34. Chen, C.H., Chen, C.Y., Lo, Y.W., Mao, C.F. and Liao, W.T., Studies of glycolysis of poly (ethylene terephthalate) recycled from postconsumer soft-drink bottles. I. Influences of glycolysis conditions. J. Appl. Polym. 80,943-948 (2001).

35. Ghaemy, M. and Mossaddegh, K., Depolymerisation of poly (ethylene terephthalate) fibre wastes using ethylene glycol. Polym. Degrad. Stabil. 90, 570-576 (2005).

36. Zhou, X., Lu, X., Wang, Q., Zhu, M. and Li, Z., Effective catalysis of poly (ethylene terephthalate)(PET) degradation by metallic acetate ionic liquids. Pure Appl. Chem 84, 789-801 (2012).

37. Wang, Q., Yao, X., Tang, S., Lu, X., Zhang, X. and Zhang, S., Urea as an efficient and reusable catalyst for the glycolysis of poly (ethylene terephthalate) wastes and the role of hydrogen bond in this process. Green Chem. 14, 2559-2566 (2012).

38. Imran, M., Kim, D.H., Al-Masry, W.A., Mahmood, A., Hassan, A., Haider, S., Ramay, S.M., Manganese-, cobalt-, and zinc-based mixed-oxide spinels as novel catalysts for the chemical recycling of poly (ethylene terephthalate) via glycolysis. Polym. Degrad. Stabil. 98, 904-915 (2013) .

39. Mishra, S. and Goje, A.S., Kinetics of glycolysis of poly (ethylene terephthalate) waste powder at moderate pressure and temperature. J. Appl. Polym. Sci. 87, 15691573 (2003).

40. Launay, A., Thominette, F. and Verdu, J., Hydrolysis of poly (ethylene terephtalate). A steric exclusion chromatography study. Polym. Degrad. Stabil. 63, 385-389 (1999).

41. Kurokawa, H., Ohshima, M., Sugiyama, K. and Miura, H., Methanolysis of polyethylene terephthalate (PET) in the presence of aluminium tiisopropoxide catalyst to form dimethyl terephthalate and ethylene glycol. Polym. Degrad. Stabil. 79, 529-533 (2003) .

42. Kao, C.Y., Cheng, W.H. and Wan, B.Z., Investigation of alkaline hydrolysis of polyethylene terephthalate by differential scanning calorimetry and thermogravimetric analysis. $J$. Appl. Polym. Sci. 70, 1939-1945 (1998). 
43. Yue, C., Fang, D., Liu, L. and Yi, T.F., Synthesis and application of task-specific ionic liquids used as catalysts and/or solvents in organic unit reactions. J. Mol. Liq. 163, 99-121 (2011).

44. Carvalho, P.J., Alvarez, V.H., Schröder, B., Gil, A.M., Marrucho, I.M., Aznar, M., Santos, L.M.N.B.F. and Coutinho, J.A.P., Specific solvation interactions of $\mathrm{CO} 2$ on acetate and trifluoroacetate imidazolium based ionic liquids at high pressures. J. Phys. Chem. B 113, 6803-6812 (2009).

45. Jiang, H., Xu, Y., Liao, S., Yu, D., Chen, H. and Li, X., A remarkable synergic effect of water-soluble bimetallic catalyst in the hydrogenation of aromatic nitrocompounds. J. Mol. Catal. A-Chem. 142,147-152 (1999).

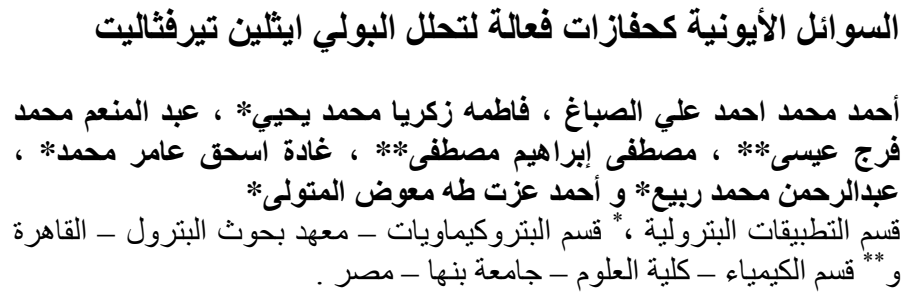

• تم اجر اء عملية تحلل البولي ايثلين تيرفتاليت باستخدام سوائل أيونية مختلفة تحت ظروف معتدلة من التفاعل.

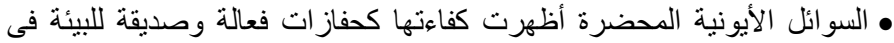

عملية تحلل البولي ايثلين تيرفتاليت فى وجود الإنئن الإثلين جليكول.

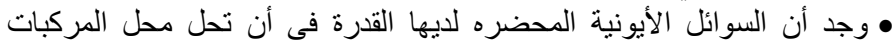

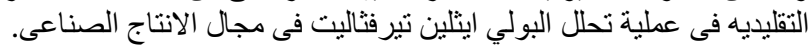

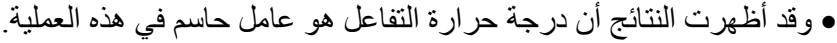

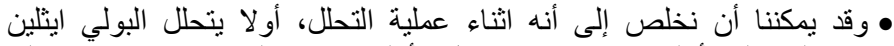

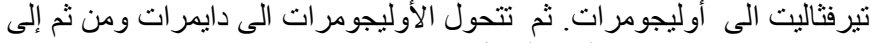

مونومر ات فى وجود اليى الإثيلين جليكول.

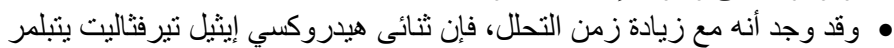

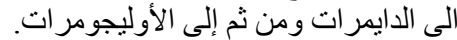

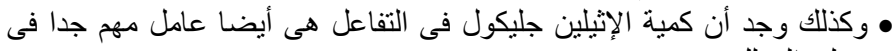
عمليه التحلل.

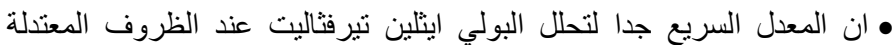

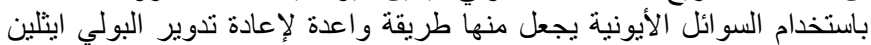

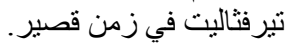

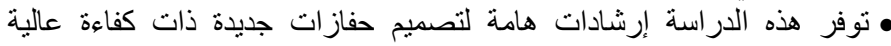
وصديقة للبيئة فى عملية تحلل البولي ايثلين تيرفناليت.

Egypt. J. Chem. 57, No. 4 (2014) 